\title{
The role of parenting and personal characteristics on deviant peer association among European American and Latino adolescents
}

Laura M. Padilla-Walker

Brigham Young University, laura_walker@byu.edu

Follow this and additional works at: https://scholarsarchive.byu.edu/facpub

Part of the Social and Behavioral Sciences Commons

\section{Original Publication Citation}

Retrieving data. Wait a few seconds and try to cut or copy again.

\section{BYU ScholarsArchive Citation}

Padilla-Walker, Laura M., "The role of parenting and personal characteristics on deviant peer association among European American and Latino adolescents" (2011). Faculty Publications. 4929.

https://scholarsarchive.byu.edu/facpub/4929 


\title{
The role of parenting and personal characteristics on deviant peer association among European American and Latino adolescents
}

\author{
Laura M. Padilla-Walker, Roy A. Bean *, Alexander L. Hsieh \\ Human Development in the School of Family Life, Brigham Young University, United States
}

\section{A R T I C L E I N F O}

Article history:

Received 4 January 2011

Received in revised form 26 May 2011

Accepted 27 May 2011

Available online 13 June 2011

\section{Keywords:}

Latinos

Parenting

Deviant peer association

Adolescents

\begin{abstract}
A B S T R A C T
This study examined both mothers' and fathers' parenting (positive and negative) and adolescents' personal characteristics (religiosity, social initiative, aggression, depression) in relation to perceived deviant peer association for European American and Latino adolescents. Using structural equation modeling, adolescents' reports of positive or negative mothering and fathering were found to be related to adolescents' personal characteristics, and these characteristics were, in turn, related to perceived deviant peer association. Ethnic differences in means were found in both parenting and outcome variables, with European American adolescents reporting higher levels of positive parenting and social initiative, and lower levels of perceived deviant peer association than Latino adolescents. Despite these mean differences, no ethnic differences were found in the overall measurement or structural model, suggesting that this process functions similarly for these two ethnic groups.
\end{abstract}

(c) 2011 Elsevier Ltd. All rights reserved.

\section{Introduction}

When examining precursors to adolescent problem behaviors, it is valuable to take a social-psychological approach, considering both personal and situational variables that interact to increase risk for, or protection against, negative outcomes. Problem behavior theory, for example, suggests that adolescents' socialization contexts (e.g., parents and peers) and personal characteristics (e.g., personality, behavior, beliefs) interact to form a web of causation that collectively contributes to adolescents' tendency toward risk behaviors (Jessor, 1998). Although this framework is helpful, additional process models (e.g., Patterson, 1986) have clarified the possible direction of effects between these variables by suggesting that tumultuous parent-child relationships often lead to noncompliant child behaviors, which continue to exacerbate these family interactions. Then, these children seek out peer contexts with similar patterns of noncompliance, which often is associated with problem behaviors in adolescence.

Despite strong support for these complex or circular theories of problem behavior, a large portion of the research literature has focused on peers' unidirectional impact on adolescent behaviors, while ignoring the simultaneous contributions of various factors to adolescent risk behaviors. In addressing this limitation, the purpose of the current study was to examine the role of parenting and youth characteristics as they relate to adolescents' deviant peer association. In addition, given the relative dearth of information on this process for ethnic minorities, the current study addressed this limitation by examining this process for both

\footnotetext{
* Corresponding author at: 258 TLRB, Provo, UT, 84602. Tel.: +1 801422 2349; fax: +1 801422163 .

E-mail address: roy_bean@byu.edu (R.A. Bean).
}

European American and Latino adolescents, as Latinos are the largest ethnic group in the United States and among the fastest growing minority populations (Guzmán, 2001).

\section{Literature review}

\subsection{The role of parenting on adolescents' personal characteristics}

Numerous studies support the continued importance of parenting on youth outcomes, including behaviors that are important predictors of adolescents' association with deviant peers. For the purposes of this study, discussion of parenting will focus on both positive and negative aspects of parenting that have been found to be particularly salient during adolescence (Steinberg, 2001). Because research has consistently highlighted the importance of parental support, autonomy, and behavioral control (often measured as parental knowledge), and the detriment of parental psychological control and authoritarian parenting (especially during adolescence; Barber, Stolz, \& Olsen, 2005; Steinberg, 2001), the current study focused on parental acceptance, autonomy granting, and knowledge as measures of positive parenting; and on psychological control, and inconsistent and harsh discipline as measures of negative parenting. In addition, in light of continued research highlighting the unique roles of mothers and fathers on child and adolescent outcomes (e.g., Barber et al., 2005; Day \& Padilla-Walker, 2009), we examined these aspects of parenting separately for mothers and fathers.

In examining how these aspects of parenting are related to characteristics and behaviors in European American and Latino youth, research suggests that parental support is negatively related to adolescents' aggression (Carlo, Roesch, \& Melby, 1998; Martinez \& Eddy, 2005) and depressive symptoms (Allen, Porter, McFarland, McElhaney, \& Marsh, 
2007; Dearing, 2004), and is positively related to adolescents' religiosity (Granqvist \& Hagekull, 1999) and social initiative (Barber et al., 2005; Bradford et al., 2004). Parental autonomy granting is related to less rebellion and less negativism, and more maturity and closeness to parents in European American and Latino adolescents (Bomar \& Sabatelli, 1996; Fuligni, 1998), while parental knowledge is related to lower levels of adolescent externalizing and internalizing behaviors (Kerr, Beck, Shattuck, Kattar, \& Uriburu, 2003; Stattin \& Kerr, 2000).

Similarly, for both European Americans and Latinos, research has demonstrated that parental psychological control is positively related to adolescent depression and antisocial behaviors (Barber et al., 2005; Bradford et al., 2004; Loukas, Paulos, \& Robinson, 2005), while coercive and authoritarian parenting is positively related to delinquent behavior and deviant peer association (Simons, Whitbeck, Conger, \& Wu, 1991). Research findings for Latino and European American populations demonstrate that inconsistent discipline is related positively to conduct problems (De La Rosa, Rice, \& Rugh, 2007; Gardner, 1989) and aggression (Sawin \& Parke, 1979); and that harsh discipline is related positively to children's aggression (Weiss, Dodge, Bates, \& Pettit, 1992) and externalizing behaviors (Eamon \& Mulder, 2005; Nix et al., 1999).

Previous research has also shown a consistent trend of healthy parenting practices/styles being negatively related to a variety of deleterious adolescent behaviors such as aggressive behavior and disobedience (Kandel, 1990), and general child behavior problems (Linville et al., 2010). Kandel (1990) found that harsh parenting disciplinary actions, or even parental discrepancies over discipline, correlates with aggressive adolescent behavior and adolescents who were at a higher risk of being disobedient to their parents. In addition, Linville et al. (2010) analyzed the relationship between parenting practices and couple satisfaction with child behavior problems and found that marital couple dissatisfaction predicted child behavior problems longitudinally. Taken together, this body of research is well-established in suggesting the salience of both positive and negative parenting, and highlights these aspects of parenting as playing a central role in the personal characteristics of adolescents.

\subsection{Personal characteristics as predictors of deviant peer association}

Although research suggests that parenting has a strong, direct correlation with adolescent deviant peer association (Simons, Whitbeck, Conger, \& Conger, 1991; Weaver \& Prelow, 2005), many studies have examined the topic without concurrently examining the individual characteristics that might incline youth toward, or away from, associations with antisocial peers. Indeed, research suggests that adolescent behaviors, interests, beliefs, personalities, and tendencies relate to their propensity to select or associate with peers who are similar to themselves (Maggs \& Galambos, 1993; Patterson, 1986; Simons et al., 1991a; Snyder et al., 2005). For example, Brown, Mounts, Lamborn, and Steinberg (1993) found that adolescent characteristics such as grade-point average, drug use, and level of self-reliance mediated the relation between parenting and adolescents' peer group affiliation. In addition, a longitudinal study by Maggs and Galambos (1993) found that adolescents' own problem behaviors mediated the relation between parent-adolescent conflict and deviant peer association. Other studies have also found that conduct problems during kindergarten (Snyder et al., 2005) and problems at school (Simons, Whitbeck, Conger, \& Conger, 1991) correlated with later deviant peer association.

To further support the role of adolescents' personal characteristics on their subsequent deviant peer association, research has found that maladaptive characteristics such as self-rejection, deviance, substance use, and problems at school are positively related to deviant peer association (Kaplan, Johnson, \& Bailey, 1987; Murguia, Chen, \& Kaplan, 1998; Simons, Whitbeck, Conger, \& Conger, 1991). Although this body of research is relatively well established, there is much less research examining positive personal characteristics that might decrease the probability that adolescents will associate with deviant peers. Although the literature regarding positive characteristics is lacking, existing studies identify personal religiosity as a protective factor mediating relations between parenting and children's risky outcomes (e.g., Kogan et al., 2008). Additionally, religiosity (e.g., Hardy \& Raffaelli, 2003) and social competence/initiative (e.g., Lansford et al., 2006) are consistently and negatively associated with negative adolescent outcomes. Thus, in an effort to study the topic utilizing a balanced approach, we examined the role of adolescents' personal characteristics that might decrease (i.e., religiosity, social initiative) or increase (i.e., aggression, depression) adolescents' tendencies to associate with deviant peers.

\subsection{Ethnicity}

The vast majority of studies examining the concurrent role of parents and peers on adolescents' deviant behavior have been conducted with European American samples, to the exclusion of Latinos (Bámaca \& Umaña-Taylor, 2006) and other ethnic groups. Although there are few studies to guide hypothesis development, research does suggest that parenting and family-level support (as a function of the cultural value of familismo) may be particularly relevant as a protective factor in helping decrease the influence of delinquent peers in the lives of Latino youth (Bámaca \& UmañaTaylor, 2006; Frauenglass, Routh, Pantin, \& Mason, 1997).

In previous studies of Latino and European American samples, ethnicity-based mean differences have been noted both in terms of parenting (e.g., Finkelstein, Donenberg, \& Martinovich, 2001; Spriggs, Iannotti, Nansel, \& Haynie, 2007) and outcomes (e.g., McLaughlin, Hilt, \& Nolen-Hoeksema, 2007). However, although findings are somewhat mixed (see Murguia et al., 1998), studies have demonstrated comparable findings between these two ethnic groups in terms of the strength and significance of relationships between specific parenting behaviors and youth outcomes (e.g., Barrera, Biglan, Ary, \& Li, 2001; Duncan, Duncan, Biglan, \& Ary, 1998), suggesting the possibility that the role of parenting and personal behaviors on deviant peer association may function similarly across these two ethnic groups. It is also important to note that mean differences, based on ethnicity, may not translate to differences that make a difference. This can be seen in studies where significant mean differences were found in scale scores for Latinos and European Americans but the associations between variables were found to be similar and even invariant across ethnic groups (e.g., Finkelstein et al., 2001; Hovell et al., 1994; Vazsonyi \& Keiley, 2007). Although we did not expect differences in associations as a function of ethnicity, because findings in this regard are somewhat mixed, in the current study we initially ran separate statistical models for European Americans and Latinos to allow us to examine the potential for both mean differences and process differences across the two ethnic groups.

\subsection{Hypotheses}

Given research suggesting the importance of both parental socialization and personal characteristics on adolescents' peer associations (Brown et al., 1993; Maggs \& Galambos, 1993; Patterson, 1986), the current study used structural equation modeling to examine how adolescents' reports of positive and negative mothering and fathering were related to adolescents' personal characteristics (positive and negative), and how these characteristics, in turn, were related to adolescents' perception of deviant peer association. First, based on existing research (Barber et al., 2005; Simons, Whitbeck, Conger, \& Conger, 1991; Weiss et al., 1992), it was expected that positive parenting would be positively related to adolescents' religiosity and social initiative, and negatively related to adolescents' aggression and depression. In turn, it was expected that negative parenting would be negatively related to adolescents' religiosity and social initiative, and positively related to adolescents' aggression and depression. Second, we hypothesized that adolescents' religiosity and 
social initiative would be negatively related, and that aggression and depression would be positively related, to the adolescent's perception of deviant peer association (Kaplan et al., 1987; Maggs \& Galambos, 1993; Simons, Whitbeck, Conger, \& Conger, 1991; Snyder et al., 2005). Despite expectations of mean differences in parenting across ethnic groups, we expected few ethnic differences in the process of how parenting and personal characteristics are associated with the adolescent's perception of deviant peer association (Finkelstein et al., 2001; Hovell et al., 1994).

\section{Method}

\subsection{Participants}

Participants were adolescents ( $M$ age $=16.08, S D=1.09$, range $=14-$ 19) who described themselves as European American $(n=848,52 \%)$ or Latino ( $n=781$ ), with slightly more female (55\%) respondents than male. About $55 \%$ of adolescents reported living with both parents, $17 \%$ reported living with their mother only, $4 \%$ reported living with their father only, $12 \%$ reported living with mother and a step-parent, and $4 \%$ reported living with other relatives. A slightly higher percentage of Latino youth reported that their family was "poorer than most other kids' families" (15.4\% versus 13.6\% for European American youth).

\subsection{Procedure}

Data were obtained from the Youth and Family Project, a 2003-2004, school-based, self-reported survey of 9-12th graders from a West Texas area school district. Based on teachers' willingness to allow surveying during class time, 4,150 students were eligible for participation and consent forms were sent home to the parents of these students. Some students were absent during survey dates and others were not able to participate due to non-returned consent forms. As such, 2292 surveys were completed for a $55.3 \%$ response rate. Because of low frequencies of other ethnic groups, data were only used for adolescents describing themselves as European American or Latino, resulting in a final study sample of 1629 adolescents. With very low numbers of students with limited English proficiency in the school district (2.6\%, compared to 16.7\% for Texas as a state, Texas Education Agency, 2008) and the participants' enrollment in high school-level English courses (where they were surveyed), the sample was determined to be moderately-tohighly acculturated.

\subsection{Measures}

\subsubsection{Parental acceptance and autonomy}

Parental acceptance and autonomy were assessed using two subscales from the revised Child Report of Parent Behavior Inventory (CRPBI; Schaefer, 1965). Adolescents responded to 10 items regarding acceptance and 8 items regarding autonomy (for both mothers and fathers) on a 3-point Likert scale ranging from $1=$ (not like her/him) to $3=$ (a lot like her/him). Sample item for acceptance includes, "makes me feel better after talking over my worries with her/him." Sample item for autonomy includes, "respects me even if I disagree with her or him." Items were averaged, resulting in a mean scale of maternal $(\alpha=.92$ for both European Americans and Latinos) and paternal ( $\alpha=.92$ for both European Americans and Latinos) acceptance, and maternal (.87 for European Americans and .84 for Latinos) and paternal ( $\alpha=.87$ for European Americans and .85 for Latinos) autonomy.

\subsubsection{Parental knowledge}

Parental knowledge was assessed using Brown et al.'s (1993) Behavioral Control Scale. Adolescents responded to 5 items for both mothers and fathers on a 3-point Likert scale ranging from $1=($ doesn't know) to $3=$ (knows a lot). Sample item includes, "How much does your parent really know who your friends are?" Items were averaged, resulting in a mean scale of maternal $(\alpha=.82$ for both European
Americans and Latinos) and paternal ( $\alpha=.88$ for European Americans and .89 for Latinos) knowledge.

\subsubsection{Parental psychological control}

Psychological control was assessed using the Psychological Control Scale-Youth Self-Report (PCS-YSR; Barber, 1996). Adolescents responded to 8 items for both mothers and fathers on a 3-point Likert scale ranging from $1=$ (not like her $/$ him $)$ to $3=($ a lot like her $/ \mathrm{him})$. Sample item includes, "If I have hurt her/his feelings, stops talking to me until I please her/him." Items were averaged, resulting in a mean scale of maternal ( $\alpha=.81$ for European Americans, .77 for Latinos) and paternal ( $\alpha=.82$ for European Americans, .80 for Latinos) psychological control.

\subsubsection{Parental discipline}

Harsh discipline was assessed using a scale established by Simons, Whitbeck, Conger, and Wu (1991), and inconsistent discipline was assessed using items devised by Barber, Chadwick, and Oeter (1992). Adolescents responded to 5 items for harsh discipline and 3 items for inconsistent discipline on a 3-point Likert scale ranging from $1=(n o t$ like her/him) to $3=($ a lot like her/him $)$. Sample item for harsh discipline includes, "Is very strict with me", while a sample item for inconsistent discipline includes, "Punishes me for things she/he previously told me were okay." Items were averaged, resulting in a mean scale of maternal ( $\alpha=.73$ for European Americans, 74 for Latinos) and paternal ( $\alpha=.75$ for European American, 76 for Latinos) harsh discipline; and maternal ( $\alpha=.78$ for European Americans, 74 for Latinos) and paternal $(\alpha=.76$ for European Americans, .70 for Latinos) inconsistent discipline.

\subsubsection{Personal religiosity}

To assess religiosity adolescents responded to 4 items (Thomas \& Carver, 1990) regarding their frequency of personal religious activities on a scale ranging from 1 (not at all) to 7(every day). Sample item includes, "Prayed privately." Scores were averaged across items $(\alpha=.84$ for European Americans, .77 for Latinos).

\subsubsection{Social initiative}

Social initiative was measured using an 8-item scale, abbreviated from the Monitoring the Future Study (Bachman, Johnston, \& O'Malley, 1993). Adolescents responded on a 5-point Likert scale ranging from $1=($ never/almost never true $)$ to $5=($ very often/always true $)$, to items indexing adolescents' efforts to initiate social interaction with peers and in group settings (e.g., "I help other students in need"). Scores were averaged across items ( $\alpha=.77$ for European Americans, 76 for Latinos).

\subsubsection{Aggression}

Adolescents' aggression was assessed using five items from the Child Behavior Checklist (CBCL; Achenbach, 1991). Each item was rated as 0 (not true) to 2 (very true or often true). Sample item includes, "I get in many fights." Scores were summed across items $(\alpha=.69$ for European Americans, .75 for Latinos).

\subsubsection{Depression}

Adolescents' depression was assessed using the Children's Depression Inventory (CDI; Kovacs, 1992). Adolescents rated 10 sets of 3 items designed to capture a range of depressive symptom presentation. Respondents marked the item that best reflected the way they have felt in the last 2 weeks from a choice of, for example, "I am sad once in a while," "I am sad many times," and "I am sad all the time." Scores were averaged across items ( $\alpha=.72$ for European Americans, .74 for Latinos).

\subsubsection{Perception of deviant peer association}

Adolescents' perceptions of deviant peer association were assessed using an 11-item scale developed by Elliott, Huizinga, and Ageton (1985). Respondents reported on a scale from 1 (none) to 5 (all), in terms of how many of their friends participate in a variety of deviant behaviors (e.g., 
purposely damage or destroy property, use marijuana). Scores were averaged across items ( $\alpha=.88$ for European Americans, .90 for Latinos).

\section{Results}

\subsection{Tests of ethnic and gender differences}

Multivariate analyses of variance (MANOVAs) were conducted to determine whether the study variables differed as a function of ethnicity (European American and Latino) and gender (boys and girls) of the child (see Table 1). The first and second analyses targeted positive mothering and fathering, and results revealed a significant multivariate main effect of adolescent ethnicity on mothering, $F(3,1456)=30.16, p<.001$; and fathering, $F(3,1423)=5.43, p<.001$; and a main effect of adolescent gender on mothering, $F(3,1456)=12.62, p<.001$; and fathering, $F(3,1456)=7.35, p<.001$. Univariate follow-up analyses using Fisher's Least Significant Differences (LSD) found that European American adolescents reported higher levels of maternal and paternal acceptance, psychological autonomy, and knowledge than did Latino adolescents. Girls reported higher maternal and paternal knowledge than did boys. The gender-by-ethnicity interaction was not significant.

The third and fourth analyses targeted negative mothering and fathering, and results revealed a significant multivariate main effect of adolescent ethnicity on mothering, $F(3,1558)=4.63, p<.01$; and fathering, $F(3,1412)=8.55, p<.001$; but there was no main effect of gender. Univariate LSD follow-up analyses found that Latino adolescents reported higher maternal psychological control and paternal harsh discipline than did European American adolescents. The gender-by-ethnicity interaction was not significant.

The fifth analysis targeted adolescents' individual characteristics, and results revealed a significant multivariate main effect of adolescent ethnicity, $F(4,1443)=24.96, p<.001$, and gender, $F(4,1443)=25.53$, $p<.001$. Univariate LSD follow-up analyses found that European American adolescents reported higher religiosity and social initia- tive, and lower aggression than did Latino adolescents. Girls reported higher religiosity, social initiative and depression than did boys. The gender-by-ethnicity interaction was not significant.

A univariate analysis of variance (ANOVA) was also conducted to determine if deviant peer association differed as a function of ethnicity and gender of the adolescent. Results revealed a significant main effect of adolescent ethnicity, $F(1,1577)=64.77, p<.001$, and gender, $F(1,1577)=18.45, p<.001$. Latino adolescents reported higher levels of perception of deviant peer association than did European American adolescents, and boys reported higher perceptions of deviant peer association than did girls. The interaction between ethnicity and gender was not significant.

\subsection{Correlations between study variables}

Bivariate correlations were conducted between all study variables, collapsed across groups because no significant differences were found between European American and Latino adolescents (see Table 2). In order to reduce the chances of Type I errors, correlations were only considered significant at the $p<.01$ level. Of particular note is that positive parenting was negatively, and negative parenting positively, associated with perceptions of deviant peer association; and religiosity and social initiative were negatively, and aggression and depression positively, associated with perceptions of deviant peer association.

\subsection{Measurement model}

Using Mplus software (Muthén \& Muthén, 2006), a measurement model was estimated including latent constructs for positive maternal and paternal parenting (as indexed by child-reported maternal and paternal acceptance, psychological autonomy, and knowledge) and negative maternal and paternal parenting (as indexed by child-reported psychological control, harsh discipline, and inconsistent discipline). A multiple group analysis where measurement invariance was tested

Table 1

Ethnic and gender differences on parenting variables and personal behaviors.

\begin{tabular}{|c|c|c|c|c|c|c|}
\hline & \multicolumn{3}{|l|}{ Ethnicity } & \multicolumn{3}{|l|}{ Gender } \\
\hline & \multirow{2}{*}{$\frac{\mathrm{EA}}{\mathrm{M}(\mathrm{SD})}$} & \multicolumn{2}{|l|}{ Latino } & \multirow{2}{*}{$\frac{\text { Boys }}{\mathrm{M}(\mathrm{SD})}$} & \multicolumn{2}{|l|}{ Girls } \\
\hline & & $\mathrm{M}(\mathrm{SD})$ & $\mathrm{F}$ & & $\mathrm{M}(\mathrm{SD})$ & $\mathrm{F}$ \\
\hline \multicolumn{7}{|l|}{ Positive Mothering } \\
\hline Acceptance & $2.44(.54)$ & $2.34(.55)$ & $11.66^{* * *}$ & $2.38(.52)$ & $2.40(.56)$ & 1.26 \\
\hline Psychological autonomy & $2.47(.51)$ & $2.40(.50)$ & $8.14^{* *}$ & $2.44(.48)$ & $2.43(.52)$ & .19 \\
\hline Knowledge & $2.47(.50)$ & $2.42(.53)$ & $5.17^{*}$ & $2.39(.52)$ & $2.49(.51)$ & $15.39^{* * *}$ \\
\hline \multicolumn{7}{|l|}{ Positive Fathering } \\
\hline Acceptance & $2.21(.57)$ & $2.14(.59)$ & $5.30^{*}$ & $2.15(.58)$ & $2.21(.58)$ & $3.87^{*}$ \\
\hline Psychological autonomy & $2.38(.52)$ & $2.28(.54)$ & $11.96^{* * *}$ & $2.31(.54)$ & $2.35(.53)$ & 2.45 \\
\hline Knowledge & $2.14(.63)$ & $2.03(.64)$ & $9.22^{* *}$ & $2.14(.64)$ & $2.05(.63)$ & $5.95^{*}$ \\
\hline \multicolumn{7}{|l|}{ Negative Mothering } \\
\hline Psychological control & $1.53(.47)$ & $1.60(.66)$ & $5.95^{*}$ & $1.53(.66)$ & $1.59(.49)$ & $3.95^{*}$ \\
\hline Harsh discipline & $1.52(.47)$ & $1.49(.48)$ & 1.64 & $1.49(.47)$ & $1.51(.48)$ & .82 \\
\hline Inconsistent discipline & $1.40(.54)$ & $1.45(.55)$ & 3.26 & $1.43(.55)$ & $1.42(.54)$ & .01 \\
\hline \multicolumn{7}{|l|}{ Negative Fathering } \\
\hline Psychological control & $1.54(.48)$ & $1.57(.49)$ & 1.25 & $1.55(.49)$ & $1.56(.48)$ & .22 \\
\hline Harsh discipline & $1.68(.53)$ & $1.58(.54)$ & $11.26^{* * *}$ & $1.66(.55)$ & $1.61(.52)$ & 3.14 \\
\hline Inconsistent discipline & $1.38(.52)$ & $1.41(.53)$ & 2.02 & $1.42(.55)$ & $1.37(.50)$ & 2.55 \\
\hline \multicolumn{7}{|l|}{ Personal Characteristics } \\
\hline Religiosity & $3.94(1.68)$ & $3.52(1.56)$ & $27.73^{* * *}$ & $3.48(1.65)$ & $3.95(1.60)$ & $33.78^{* * *}$ \\
\hline Social initiative & $3.02(.79)$ & $2.69(.76)$ & $69.09^{* * *}$ & $2.68(.78)$ & $3.01(.76)$ & $71.59^{* * *}$ \\
\hline Aggression & $.77(1.38)$ & $1.21(1.86)$ & $23.98^{* * *}$ & $.99(1.60)$ & $.96(1.62)$ & .16 \\
\hline Depression & $1.38(35)$ & $1.39(.37)$ & .03 & $1.33(.32)$ & $1.44(.37)$ & $34.08^{* * *}$ \\
\hline Deviant Peer Association & $1.64(.63)$ & $1.92(.78)$ & $64.77^{* * *}$ & $1.85(.76)$ & $1.71(.68)$ & $18.45^{* * *}$ \\
\hline
\end{tabular}

${ }^{*} \mathrm{p}<.05,{ }^{* *} \mathrm{p}<.01,{ }^{* * *} \mathrm{p}<.001$. 
Table 2

Correlations between parenting variables, individual behaviors, and deviant peer association.

\begin{tabular}{|c|c|c|c|c|c|c|c|c|c|c|c|c|c|c|c|c|}
\hline & 1 & 2 & 3 & 4 & 5 & 6 & 7 & 8 & 9 & 10 & 11 & 12 & 13 & 14 & 15 & 16 \\
\hline 1. Maternal acceptance & - & & & & & & & & & & & & & & & \\
\hline 2. Maternal autonomy & $.82^{* *}$ & - & & & & & & & & & & & & & & \\
\hline 3. Maternal knowledge & $.49^{* *}$ & $.47^{* *}$ & - & & & & & & & & & & & & & \\
\hline 4. Paternal acceptance & $.44^{* *}$ & $.34^{* *}$ & $.20^{* *}$ & - & & & & & & & & & & & & \\
\hline 5. Paternal autonomy & $.41^{* *}$ & $.48^{* *}$ & $.23^{* *}$ & $.80^{* *}$ & - & & & & & & & & & & & \\
\hline 6. Paternal knowledge & $.25^{* *}$ & $.22^{* *}$ & $.44^{* *}$ & $.55^{* *}$ & $.48^{* *}$ & - & & & & & & & & & & \\
\hline 7. M psychological control & $-.47^{* *}$ & $-.54^{* *}$ & $-.29^{* *}$ & $-.20^{* *}$ & $-.25^{* *}$ & $-.20^{* *}$ & - & & & & & & & & & \\
\hline 8. M harsh discipline & $-.21^{* *}$ & $-.29^{* *}$ & $-.14^{* *}$ & .02 & -.05 & .03 & $.41^{* *}$ & - & & & & & & & & \\
\hline 9. M inconsistent discipline & $-.40^{* *}$ & $-.47^{* *}$ & $-.30^{* *}$ & $-.17^{* *}$ & $-.23^{* *}$ & $-.19^{* *}$ & $.56^{* *}$ & $.44^{* *}$ & - & & & & & & & \\
\hline 10. P psychological control & $-.20^{* *}$ & $-.24^{* *}$ & $-.17^{* *}$ & $-.52^{* *}$ & $-.61^{* *}$ & $-.36^{* *}$ & $.36^{* *}$ & $.18^{* *}$ & $.29^{* *}$ & - & & & & & & \\
\hline 11. $P$ harsh discipline & -.06 & $-.12^{* *}$ & -.03 & $-.18^{* *}$ & $-.27^{* *}$ & $-.07^{*}$ & $.19^{* *}$ & $.46^{* *}$ & $.23^{* *}$ & $.50^{* *}$ & - & & & & & \\
\hline 12. $\mathrm{P}$ inconsistent discipline & $-.17^{* *}$ & $-.20^{* *}$ & $-.13^{* *}$ & $-.34^{* *}$ & $-.45^{* *}$ & $-.23^{* *}$ & $.29^{* *}$ & $.20^{* *}$ & $.52^{* *}$ & $.65^{* *}$ & $.47^{* *}$ & - & & & & \\
\hline 13. Religiosity & $.16^{* *}$ & $.15^{* *}$ & $.24^{* *}$ & $.19^{* *}$ & $.17^{* *}$ & $.19^{* *}$ & $-.07^{*}$ & .05 & $-.09^{* *}$ & $-.10^{* *}$ & .01 & $-.10^{* *}$ & - & & & \\
\hline 14. Social initiative & $.26^{* *}$ & $.20^{* *}$ & $.22^{* *}$ & $.25^{* *}$ & $.22^{* *}$ & $.16^{* *}$ & $-.06^{*}$ & $.09^{*}$ & -.06 & $-.09^{* *}$ & $.10^{* *}$ & -.01 & $.37^{* *}$ & - & & \\
\hline 15. Aggression & $-.25^{* *}$ & $-.25^{* *}$ & $-.24^{* *}$ & $-.18^{* *}$ & $-.20^{* *}$ & $-.18^{* *}$ & $.30^{* *}$ & $.16^{* *}$ & $.22^{* *}$ & $.21^{* *}$ & $.12^{* *}$ & $.16^{* *}$ & $-.18^{* *}$ & $-.16^{* *}$ & - & \\
\hline 16. Depression & $-.35^{* *}$ & $-.37^{* *}$ & $-.21^{* *}$ & $-.32^{* *}$ & $-.34^{* *}$ & $-.25^{* *}$ & $.33^{* *}$ & $.21^{* *}$ & $.29^{* *}$ & $.33^{* *}$ & $.16^{* *}$ & $.26^{* *}$ & $-.11^{* *}$ & $-.16^{* *}$ & $.30^{* *}$ & - \\
\hline 17. Deviant peer association & $-.24^{* *}$ & $-.24^{* *}$ & $-.35^{* *}$ & $-.20^{* *}$ & $-.22^{* *}$ & $-.27^{* *}$ & $.23^{* *}$ & $.11^{* *}$ & $.21^{* *}$ & $.20^{* *}$ & $.06^{*}$ & $.16^{* *}$ & $-.26^{* *}$ & $-.21^{* *}$ & $.50^{* *}$ & $.19^{* *}$ \\
\hline
\end{tabular}

${ }^{*} \mathrm{p}<.01,{ }^{* *} \mathrm{p}<.001$. Across correlational analyses, n's ranged from 1255 to 1608 .

across ethnicity revealed that factor loadings were not different for European Americans and Latinos (see Fig. 1). Similar analyses were conducted for gender, and factor loadings were not different for males and females. Estimation of the measurement model yielded an acceptable fit, $X^{2}(42)=360.191, p<.001, \mathrm{CFI}=.968$, RMSEA $=.068$, $\mathrm{SRMR}=.045$, and all factor loadings were statistically significant at .53 or above (see Fig. 1 ).

\subsection{Structural model}

Next, a structural model was estimated, modeling positive and negative mothering and fathering as predictors of adolescents' individual characteristics (religiosity, social initiative, aggression, and depression). In turn, adolescent characteristics were used as predictors of adolescents' deviant peer association. The default model (wherein factor loadings were constrained to be equal across groups) was compared to a model where all structural paths were freely estimated across groups. A non-significant chi-square difference between the two models $\left(X^{2}=(28) 2.63\right.$, ns.) suggested that the structural paths were not different, or that the model did not function differently by ethnicity. Similar analyses were conducted for gender, and a non-significant chi-square difference between the two models $\left(X^{2}=(19) 23.62\right.$, ns) suggested that the structural paths were not different for males and females. However, due to the mean differences noted on outcome variables as a function of gender, it was included as a control in the structural analysis (not shown in the figure for parsimony). Thus, the final model is a single group, with both European American and Latino adolescents combined (see Fig. 2).

Model fit indices suggested adequate fit, $X^{2}(89)=539.889$, $p<.001 ;$ CFI $=.962$, RMSEA $=.056$, SRMR $=.043$. Results revealed that: (a) positive mothering and positive fathering were positively related to religiosity, (b) mothering (positive and negative) and positive fathering were positively related to adolescents' social initiative, (c) positive fathering was negatively and negative mothering was positively related to aggression, (d) positive mothering and fathering were negatively, and negative mothering and fathering were positively related to depression, and (e) religiosity and social initiative were negatively, and aggression was positively related to perception of deviant peer association. Child gender was related positively to religiosity $(\beta=.12, p<.001$; females had the higher coded value), social initiative $(\beta=.19, p<.001)$, and depression $(\beta=.14, p<.001)$.

Although none of the parenting variables were directly related to perception of deviant peer association after accounting for the child's personal characteristics, tests of indirect effects found that positive mothering was indirectly related to perception of deviant peer association via adolescents' religiosity $(\beta=-.04, p<.01)$ and social initiative $(\beta=$ $-.04, p<.01$ ), and positive fathering was indirectly related to perception of deviant peer association via adolescents' religiosity $(\beta=-.02, p<.05)$, social initiative $(\beta=-.02, p<.05)$, and aggression $(\beta=-.04, p<.05)$. Together, the model accounted for $7 \%$ of explained variance in religiosity, $15 \%$ in social initiative, $13 \%$ in aggression, $27 \%$ in depression, and $30 \%$ in perception of deviant peer association.

\section{Discussion}

The purpose of the current study was two-fold. First, we sought to test a model examining the role of parenting and adolescents' personal characteristics on deviant peer association. Second, the current study examined whether the proposed model fit for both European Americans and Latinos. Findings were generally consistent with hypotheses, with parenting related to adolescents' personal characteristics, and characteristics (in turn) related to perception of deviant peer association. Additionally, the model did not vary as a function of ethnicity. This study provides support for the importance of adolescents' personal characteristics as mediators between parenting and perception of deviant peer association, for both European American and Latino youth.

\subsection{The role of parenting on adolescents' personal characteristics}

For both European American and Latino adolescents, perceptions of both mothering and fathering were consistently related to adolescents' personal characteristics. More specifically, positive mothering and fathering were related to higher levels of adolescent religiosity and social initiative, and lower levels of aggression (in relation to fathers' parenting only) and depression. In turn, negative mothering seemed to be more salient than negative fathering, in that negative mothering was positively related to social initiative, aggression, and depression, while negative fathering was only positively related to depression. Taken together, these findings confirm and add to existing literature in a number of meaningful ways. First, these findings are consistent with existing research suggesting that despite the increased distance between children and parents during adolescence (Buhrmester \& Carbery, 1992), parenting continues to be importantly related to adolescents' personal characteristics and behaviors (Allen et al., 2007; Barber et al., 2005). Second, the current study extends existing research by highlighting not only the importance of positive mothering, but of positive fathering as well. Although an increasing number of studies are 


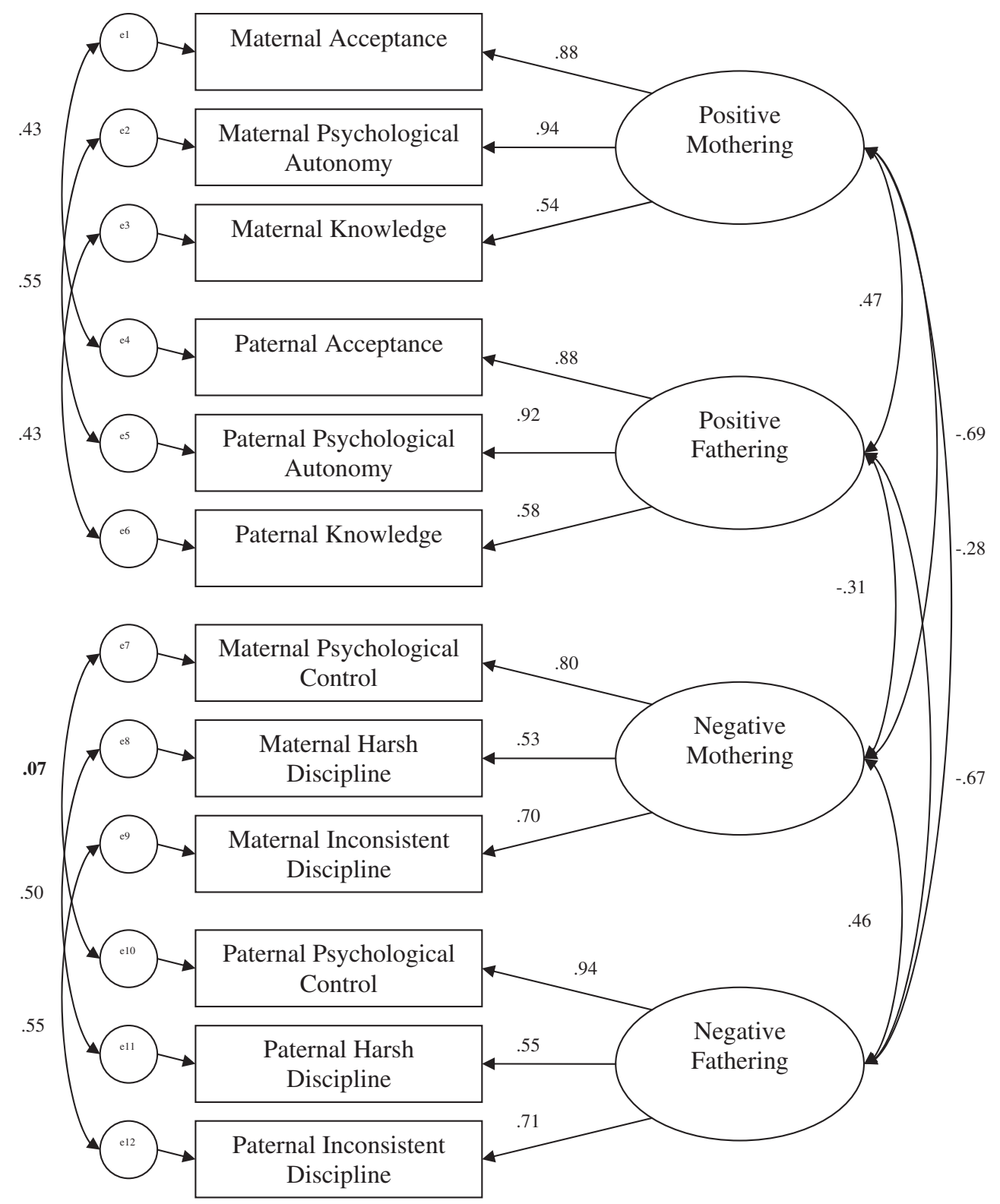

Note. $X^{2}(42)=360.191, p<.001, \mathrm{CFI}=.968, \mathrm{RMSEA}=.068, \mathrm{SRMR}=.045$. All weights are standardized and significant at $p<.001$ except those in bold, which are nonsignificant.

Fig. 1. Measurement model of positive and negative mothering and fathering.

focusing on fathers as well as mothers, these findings build on recent studies suggesting the unique importance of fathers, particularly in relation to externalizing and internalizing behaviors (Barber et al., 2005; Day \& Padilla-Walker, 2009). Further, our findings related to the influence of fathers during adolescence is particularly important in the case of Latino families, as the majority of the available research for this group has focused on mothers and young children, thereby, neglecting both fathering and the impact of parenting on adolescent children (Harwood, Leyendecker, Carlson, Asencio, \& Miller, 2002).

\subsection{Correlates of deviant peer association}

As hypothesized, positive personal characteristics (i.e., religiosity and social initiative) were negatively with adolescent's perception of deviant peer association while aggression was positively associated with this same outcome. These findings are consistent with past research linking adolescent aggression and delinquency to associations with perception of deviant peers (Patterson, DeBaryshe, \& Ramsey, 1989), and extend this research by highlighting the importance of positive personal characteristics as mediators between parenting and perception of deviant peer association. Given the body of research suggesting direct relations between parenting and deviant peer association (e.g., Simons, Whitbeck, Conger, \& Wu, 1991), these findings are an important reminder that adolescents' personal characteristics (both positive and negative) are often the mechanisms through which parenting asserts its influence. Indeed, in the current study, parenting was more strongly related directly to adolescents' personal behaviors than it was indirectly to deviant peer association, suggesting that especially as adolescents get older, their own personal values and characteristics are more strongly related to outcomes than is parenting (e.g., Kogan et al., 2008; Steinberg \& Silk, 2002). Again, this does not suggest that parents are not important during adolescence, but merely 


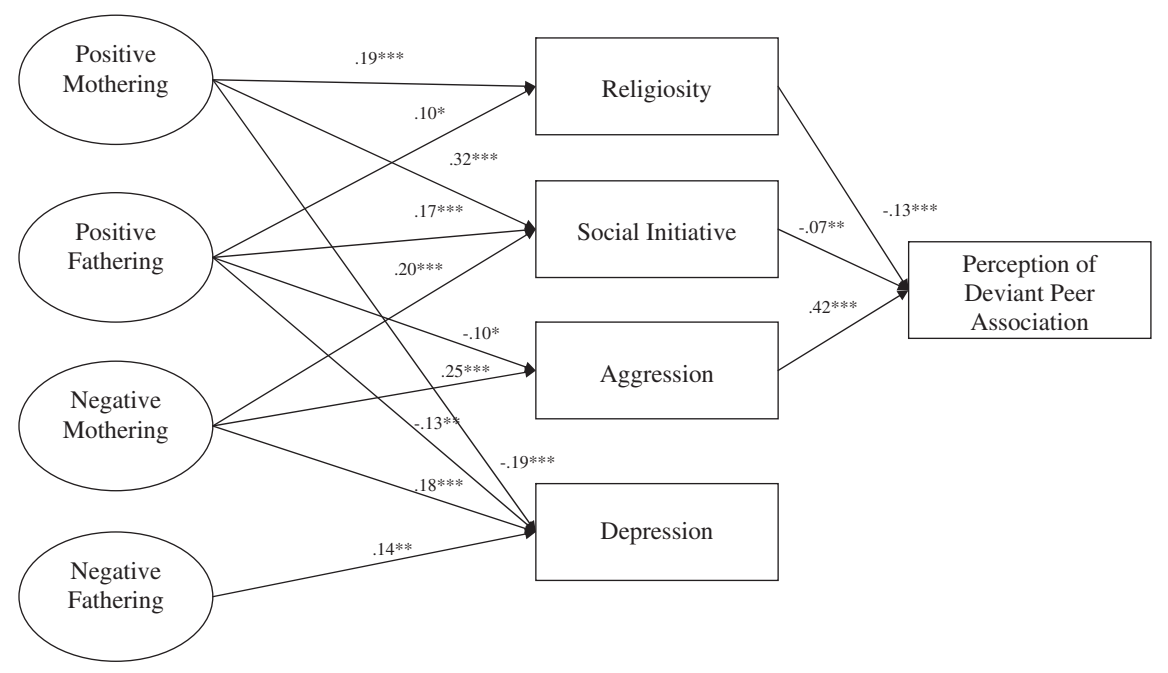

Note. All weights are standardized. $\mathrm{X}^{2}(89)=539.888, \mathrm{p}<.001 ; \mathrm{CFI}=.962, \mathrm{RMSEA}=.056, \mathrm{SRMR}=.043$. Variables represented by ovals are latent variables. Omitted from the figure are nonsignificant paths, and error and latent variable covariances. $* \mathrm{p}<.05, * * \mathrm{p}<.01, * * * \mathrm{p}<.01$.

Fig. 2. Structural model of parenting and individual behaviors as predictors of European American and Latino adolescents' deviant peer association.

that parental influence changes as socialization efforts are displayed in adolescents' own self-regulated behaviors and values.

\subsection{Clinical implications}

Our study has several implications that can be clinically useful. First, it draws attention to the relative importance of paternal parenting (and not just mothering) in terms of adolescent behaviors and deviant peer association. Whereas, the large majority of studies examining these topics in Latino families have focused almost exclusively on maternal parenting (e.g., Loukas, Prelow, Suizzo, \& Allua, 2008; Prelow, Loukas, \& JordanGreen, 2007), this study notes significant relationships to adolescent outcomes for both mothers and fathers. These findings draw attention to the importance of fathering as it is significantly related to the adolescent personal characteristics and to deviant peer association. In fact, based on these findings, there is clear evidence for a clinical focus on parentadolescent interactions when providing mental health services to adolescents struggling with these difficulties. More specifically, it recommended that a detailed evaluation of parenting behaviors be conducted in order to develop an effective treatment plan and to assess the parents' potential as a key relational resource. Also, unless contraindicated in cases of violence or abuse, the significance of the relationships between parenting behaviors and youth outcomes provides support for treating parents and children together in family therapy.

With this study's specific inclusion of Latino adolescents, there was a targeted focus to increase the field's understanding of this understudied group. In general, the findings suggest that parental practices have a strong correlation with adolescent characteristics and youth perceptions of peer deviant association in this population. Considering Latino families, this finding may be explained as a function of Latino families being regarded as highly familial (familismo), with a high level of cohesion in family relationships (Falicov, 1998; Sarkisian, Gerena, \& Gerstel, 2006). This provides additional support for the cultural relevance of family therapy as key aspect of treatment for Latinos (Falicov, 1998). In many Latino families, substantial attention is paid to child-rearing, especially during the critical adolescent years as parenting is seen as an important societal or civil duty. For clinicians working with Latinos, attention should be paid regarding the influence of parents in the lives of their adolescent. In addition to the direct influence that family therapy can have on decreasing problem behavior at the time of therapy (Santisteban \& Szapocznik, 1994; Santisteban et al., 1996), it is also possible that extensive parent-child therapeutic interventions throughout the course of therapy may help guard adolescents from later problems and/or help protect younger siblings against deviant peer association and other maladaptive behaviors.

\subsection{Limitations and future directions}

While valuable in terms of its size and ethnic diversity, the current sample is limited by the fact that it allows only for cross-sectional data analyses, highlighting the need for longitudinal data to determine causality in the associations as theorized. Past research suggests a dynamic and reciprocal process wherein adolescents' personal characteristics are predictive of the peers that they select (Brown et al., 1993), and once selected into a peer group, socialization effects also begin to influence behavior (Vitaro, Tremblay, Kerr, Pagani, \& Bukowski, 1997). Thus, it is likely that the current study did not fully capture the bidirectionality of the peer relationship. In addition, there was no external confirmation of adolescents' reports of deviant peer association, so it is possible that the adolescents projected their own values and behaviors on their friends, which inflates similarity. In addition, although the current dataset was relatively rich in terms of ethnic heterogeneity, there were generally low levels of deviant peer association given the community sample, and although this limits generalizability to clinical samples, it provides important information on the process for a relatively normative sample. Finally, given the lack of precision in measuring the sample's acculturation level, the relationships examined in the model require additional study to better understand the influence of acculturation in relation to parenting behaviors and youth outcomes.

Despite these limitations, the current study adds to the field's understanding of the role of peer influence in a number of meaningful ways. Findings were consistent with research suggesting that while peers are important during adolescence, they likely do not have the influence to derail adolescents from behaviors that are already likely, due to a combination of parental influence and personal or genetic characteristics or vulnerabilities. Although deviant peers are likely to make a bad situation worse, future research should 
continue to examine the dynamic relation between parents, peers, and individual characteristics as they relate to adolescents' positive and negative outcomes.

Furthermore, the current study added to existing literature by extending models of peer relations to both European American and Latino adolescents. These findings have important implications for intervention aimed at helping a diverse group of adolescents. More specifically, they highlight the importance of efforts not only to reduce aggression and delinquent behavior, but also to encourage and foster positive characteristics and behavior such as social initiative and religiosity, with the end goal aimed at avoiding the perpetuation of deviance that often results from associations with deviant peers (Dodge, Dishion, \& Lansford, 2006).

\section{References}

Achenbach, T. M. (1991). Manual for the youth self-report and 1991 profile. Burlington: University of Vermont, Department of Psychiatry.

Allen, J. P., Porter, M., McFarland, C., McElhaney, K. B., \& Marsh, P. (2007). The relation of attachment security to adolescents' paternal and peer relationships, depression, and externalizing behavior. Child Development, 78, 1222-1239.

Bachman, G. G., Johnston, L. D., \& O'Malley, P. M. (1993). Monitoring the future: A continuing study of the lifestyles and values of youth 1992. Ann Arbor, MI: Interuniversity Consortium for Political and Social Research.

Bámaca, M. Y., \& Umaña-Taylor, A. J. (2006). Testing a model of resistance to peer pressure among Mexican-origin adolescents. Journal of Youth and Adolescence, 35 631-645.

Barber, B. K. (1996). Parental psychological control: Revisiting a neglected construct. Child Development, 67, 3296-3319.

Barber, B. K., Chadwick, B. A., \& Oeter, R. (1992). Parental behaviors and adolescent self esteem in the U.S. and Germany. Journal of Marriage and the Family, 54, 128-141.

Barber, B. K., Stolz, H. E., \& Olsen, J. A. (2005). Parental support, psychological control, and behavioral control: Assessing relevance across time, culture, and method. Monographs of the Society for Research in Child Development, 70.

Barrera, M., Biglan, A., Ary, D., \& Li, F. (2001). Replication of a problem behavior model with American Indian, Latino and Caucasian youth. Journal of Early Adolescence, 21, 133-157.

Bomar, J. A., \& Sabatelli, R. M. (1996). Family system dynamics, gender, and psychological maturity in late adolescence. Journal of Adolescent Research, 11, 421-439.

Bradford, K., Barber, B., Olsen, J., Maughan, S., Erickson, L., Ward, D., et al. (2004). A multi-national study of interparental conflict, parenting, and adolescent functioning: South Africa, Bangladesh, China, India, Bosnia, Germany, Palestine, Colombia, and the United States. Marriage E' Family Review, 35(3), 107-137.

Brown, B. B., Mounts, N., Lamborn, S. D., \& Steinberg, L. (1993). Parenting practices and peer group affiliation in adolescence. Child Development, 63, 391-400.

Buhrmester, D., \& Carbery, J. (1992). Daily patterns of self-disclosure and adolescent adjustment. Paper presented at the biennial meeting of the Society for Research on Adolescence, Washington, D.C.

Carlo, G., Roesch, S. C., \& Melby, J. (1998). The multiplicative relations of parenting and temperament to prosocial and antisocial behaviors in adolescence. Journal of Early Adolescence, 18, 266-290.

Day, R. D., \& Padilla-Walker, L. M. (2009). Mother and father connectedness and involvement during early adolescence. Journal of Family Psychology, 23, 900-904.

De La Rosa, M., Rice, C., \& Rugh, D. (2007). Understanding Latino family attitudes in relation to Latino gang members' substance abuse: A content analysis. Journal of Human Behavior in the Social Environment, 16(4), 1-18.

Dearing, E. (2004). The developmental implications of restrictive and supportive parenting across neighborhoods and ethnicities: Exceptions are the rule. Journal of Applied Developmental Psychology, 25(5), 555-575.

Dodge, K. A., Dishion, T. J., \& Lansford, J. E. (2006). Deviant peer influences in programs for youth. New York: Guilford Press.

Duncan, S. C., Duncan, T. E., Biglan, A., \& Ary, D. (1998). Contributions of the social context to the development of adolescent substance abuse: A multivariate latent growth modeling approach. Drug and Alcohol Dependence, 50, 57-71.

Eamon, M., \& Mulder, C. (2005). Predicting antisocial behavior among Latino young adolescents: An ecological systems analysis. The American Journal of Orthopsychiatry, 75(1), 117-127.

Elliott, D. S., Huizinga, D., \& Ageton, S. (1985). Explaining delinquency and drug use. Beverly Hills, CA: Sage.

Falicov, C. J. (1998). Latino families in therapy: A guide to multicultural practice. New York New York: Guilford Press.

Finkelstein, J. S., Donenberg, G. R., \& Martinovich, Z. (2001). Maternal control and adolescent depression: Ethnic differences among clinically referred girls. Journal of Youth and Adolescence, 30, 155-171.

Frauenglass, S., Routh, D. K., Pantin, H. M., \& Mason, C. A. (1997). Family support decreases influence of deviant peers on Latino adolescents' substance abuse. Journal of Clinical Child Psychology, 26, 15-23.

Fuligni, A. J. (1998). Authority, autonomy, and parent-adolescent conflict and cohesion: A study of adolescents from Mexican, Chinese, Filipino, and European backgrounds. Developmental Psychology, 34(4), 782-792.

Gardner, F. E. (1989). Inconsistent parenting: Is there evidence for a link with children's conduct problems? Journal of Abnormal Child Psychology, 17, 223-233.
Granqvist, P., \& Hagekull, B. (1999). Religiousness and perceived childhood attachment: Profiling socialized correspondence and emotional compensation. Journal for the Scientific Study of Religion, 38, 254-273.

Guzmán, B. (2001). The Latino population. Census 2000 brief. Retrieved November 30, 2007 from. http://www.census.gov/prod/2001 pubs/c2kbr01-3.pdf

Hardy, S. A., \& Raffaelli, M. (2003). Adolescent religiosity and sexuality: An investigation of reciprocal influences. Journal of Adolescence, 26, 731-739.

Harwood, R., Leyendecker, B., Carlson, V., Asencio, M., \& Miller, A. (2002). Parenting among Latino families in the U.S. In M. H. Bornstein (Ed.), Handbook of parenting: Vol. 4: Social conditions and applied parenting (pp. 21-46). (2nd ed). Mahwah, NJ: Erlbaum.

Hovell, M., Sipan, C., Blumber, E., Atkins, C., Hofstetter, C. R., \& Kreitner, S. (1994). Family influences on Latino and Anglo adolescents' sexual behavior. Journal of Marriage and the Family, 56, 973-986.

Jessor, R. (1998). New perspectives on adolescent risk behavior. New York, NY: Cambridge University Press.

Kandel, D. B. (1990). Parenting styles, drug use, and children's adjustment in families of young adults. Journal of Marriage and Family, 52(1), 183-196.

Kaplan, H. B., Johnson, R. J., \& Bailey, C. A. (1987). Deviant peers and deviant behavior: Further elaboration of a model. Social Psychology Quarterly, 50, 277-284.

Kerr, M., Beck, K., Shattuck, T., Kattar, C., \& Uriburu, D. (2003). Family involvement, problem and prosocial behavior outcomes of Latino Youth. American Journal of Health Behavior, 27, 55-65.

Kogan, S. M., Brody, G. H., Gibbons, F. X., Murry, V. M., Cutron, C. E., Simons, R. L., et al. (2008). The influence of role status on risky sexual behavior among African Americans during the transition to adulthood. Journal of Black Psychology, 34, 399-420.

Kovacs, M. (1992). Children's depression inventory. Niagara Falls, NY: Multi-Health Systems.

Lansford, J. E., Putallaz, M., Grimes, C. L., Schiro-Osman, K. A., Kupersmidt, J. B., \& Coie, J. D. (2006). Perceptions of friendship quality and observed behaviors with friends: How do sociometrically rejected, average, and popular girls differ? Merrill-Palmer Quarterly, $52,694-720$

Linville, D., Chronister, K., Dishion, T., Todahl, J., Miller, J., Shaw, D., et al. (2010). A longitudinal analysis of parenting practices, couple satisfaction, and child behavior problems. Journal of Marital and Family Therapy, 36(2), 244-255.

Loukas, A., Paulos, S., \& Robinson, S. (2005). Early adolescent social and overt aggression: Examining the roles of social anxiety and maternal psychological control. Journal of Youth and Adolescence, 34(4), 335-345.

Loukas, A., Prelow, H. M., Suizzo, M. -A., \& Allua, S. (2008). Mothering and peer associations mediate cumulative risk effects of Latino youth. Jounraml of Marriage and Family, 70, 76-85.

Maggs, J. L., \& Galambos, N. L. (1993). Alternative structural models for understanding adolescent problem behavior in two-earner families. Journal of Early Adolescence, $13,79-101$

Martinez, C., \& Eddy, J. (2005). Effects of culturally adapted parent management training on Latino youth behavioral health outcomes. Journal of Consulting and Clinical Psychology, 73(5), 841-851.

McLaughlin, K. A., Hilt, L. M., \& Nolen-Hoeksema, S. (2007). Racial/ethnic differences in internalizing and externalizing symptoms in adolescents. Journal of Abnormal Child Psychology, 35, 801-816.

Murguia, E., Chen, Z., \& Kaplan, H. B. (1998). A comparison of causal factors in drug use among Mexican American and Non-Latino Whites. Social Science Quarterly, 79, 341-360.

Muthén, L. K., \& Muthén, B. O. (2006). Mplus user guide (4th ed.). Los Angeles: Muthén \& Muthén.

Nix, R. L., Pinderhughes, E. E., Dodge, K. A., Bates, J. E., Pettit, G. S., \& McFadyen-Ketchum, S. A. (1999). The relation between mothers' hostile attribution tendencies and children's externalizing behavior problems: The mediating role of mothers' harsh discipline practices. Child Development, 70, 896-909.

Patterson, G. R. (1986). Performance models for antisocial boys. The American Psychologist, 41, 432-444.

Patterson, G. R., DeBaryshe, B. D., \& Ramsey, E. (1989). A developmental perspective on antisocial behavior. The American Psychologist, 44, 329-355.

Prelow, H. M., Loukas, A., \& Jordan-Green, L. (2007). Socioenvironmental risk and adjustment in Latino youth: The mediating effects of family process and social competence. Journal of Youth and Adolescence, 36, 465-476.

Santisteban, D., \& Szapocznik, J. (1994). Bridging theory, research and practice to more successfully engage substance abusing youth and their families into therapy. Journal of Child and Adolescent Substance Abuse, 3, 9-24.

Santisteban, D. A., Szapocznik, J., Perez-Vidal, A., Kurtines, W. M., Murray, E. J., \& LaPerriere, A. (1996). Efficacy of intervention for engaging youth and families into treatment and some variables that may contribute to differential effectiveness. Journal of Family Psychology, 10, 35-44.

Sarkisian, N., Gerena, M., \& Gerstel, N. (2006). Extended family ties among Mexican, Puerto Ricans, and Whites: Superintegration or disintegration? Family Relations, 55, 331-344.

Sawin, D. B., \& Parke, R. D. (1979). Inconsistent discipline of aggression in young boys. Journal of Experimental Child Psychology, 28, 525-538.

Schaefer, E. S. (1965). Children's reports of parental behavior: An inventory. Child Development, 36(2), 413-424.

Simons, R. L., Whitbeck, L. B., Conger, R. D., \& Conger, K. J. (1991). Parenting factors, social skills, and value commitments as precursors to school failure, involvement with deviant peers, and delinquent behavior. Journal of Youth and Adolescence, 20, 645-664.

Simons, R. L., Whitbeck, L. B., Conger, R. D., \& Wu, C. (1991). Intergenerational transmission of harsh parenting. Developmental Psychology, 27, 159-171.

Snyder, J., Schrepferman, L., Oeser, J., Patterson, G., Stoolmiller, M., Johnson, K., et al. (2005). Deviancy training and association with deviant peers in young children: 
Occurrence and contribution to early-onset conduct problems. Development and Psychopathology, 17, 397-413.

Spriggs, A. L., Iannotti, R. J., Nansel, T. R., \& Haynie, D. L. (2007). Adolescent bullying involvement and perceived family, peer, and school relations: Commonalities and differences across race/ethnicity. The Journal of Adolescent Health, 41, 283-293.

Stattin, H., \& Kerr, M. (2000). Parental monitoring: A reinterpretation. Child Development, $71,1072-1085$.

Steinberg, L. (2001). We know some things: Parent-adolescent relationships in retrospect and prospect. Journal of Research on Adolescence, 11, 1-19.

Steinberg, L., \& Silk, J. S. (2002). Parenting adolescents. In M. H. Bornstein (Ed.), Handbook of parenting: Vol. 1: Children and parenting (pp. 103-133). (2nd ed). Mahwah, NJ: Erlbaum.

Texas Education Agency (2008). Academic indicator system: LISD. Retrieved June 10, 2009 from. http://www.lubbockisd.org/StudentAssessment/2008_AEIS/Lubbock_ISD.pdf

Thomas, D. L., \& Carver, C. (1990). Religion and adolescent social competence. In D. L. Thomas (Ed.), Developing social competency in adolescence (pp. 195-219). Newbury Park, CA: Sage.
Vazsonyi, A. T., \& Keiley, M. K. (2007). Normative developmental trajectories of aggressive behaviors in African American, American Indian, Asian American, Caucasian, and Latino children and early adolescents. Journal of Abnormal Child Psychology, 35, 1047-1062.

Vitaro, F., Tremblay, R. E., Kerr, M., Pagani, L., \& Bukowski, W. M. (1997). Disruptiveness, friends' characteristics, and delinquency in early adolescence: A test of two competing models of development. Child Development, 68, 676-689.

Weaver, S. R. \& Prelow, H. M. (2005). A mediated-moderation model of maternal parenting style, association with deviant peers, and problem behaviors in urban African American and European American adolescents. Journal of Child and Family Studies, 14, 343-356.

Weiss, B., Dodge, K. A., Bates, J. E., \& Pettit, G. S. (1992). Some consequences of early harsh discipline: Child aggression and a maladaptive social information processing style. Child Development, 63, 1321-1335. 